\title{
Surgical assessment of urethrostomy wound healing with silk or nylon suture in a male cat
}

\author{
Tanveer Hussain Khaskheli $^{{ }^{*}}$, Ahmed Nawaz Tunio ${ }^{1}$, Jay Kumar \\ Soothar $^{1}$, Sundesh Kumar Oad ${ }^{1}$, Jawed Ali Dhiloo ${ }^{1}$, Kamran Ilahi Tunio ${ }^{2}$ \\ and Muhammad Ismail Brohi ${ }^{3}$
}

1. Department of Veterinary Surgery and Obstetrics, Sindh Agriculture University Tandojam, Pakistan

2. Department of Poultry Husbandry, Sindh Agriculture University Tandojam, Pakistan

3. Department of Animal Reproduction, Sindh Agriculture University Tandoajm, Pakistan

*Corresponding author's email: tanveerhussain529@gmail.com

Citation

Tanveer Hussain Khaskheli, Ahmed Nawaz Tunio, Jay Kumar Soothar, Sundesh Kumar Oad, Jawed Ali Dhiloo, Kamran Ilahi Tunio and Muhammad Ismail Brohi. Surgical assessment of urethrostomy wound healing with silk or nylon suture in a male cat. Pure and Applied Biology. Vol. 10, Issue 2, pp399-405.

http://dx.doi.org/10.19045/bspab.2021.100043

Received: 09/06/2020 Revised: 24/08/2020

Accepted: 07/09/2020

Online First: 30/09/2020

\section{Abstract}

The study was conducted on 12 healthy male cats to assess skin wound healing and determine complications of wound healing in cats between silk and nylon suture material after perineal urethrostomy. Two groups were made for suturing material; group A (Silk 3/0) and group B (Nylon 3/0). Animals were premedicated with Acepromazine $0.03 \mathrm{mg} / \mathrm{kg}$ and xylazine $0.5 \mathrm{mg} / \mathrm{kg}$ were given intramuscularly for sedation. Ketamine $6 \mathrm{mg} / \mathrm{kg}$ body weight was administered intramuscularly for anesthesia. The penis and scrotal area were surgically separated in ventral and lateral direction. Ventral ligament of the penis and ischiocavernosum muscles were seprated. Tom catheter (14 $\mathrm{mm}$ diameter) was placed into urethra and a $(1-\mathrm{cm})$ long incision was made into urethral canal. Pencillin $\mathrm{G}$ at $0.5 \mathrm{cc}$ and meloxicam $0.3 \mathrm{cc}$ was given intramuscular till recovery. Cats were monitored for 10 days for wound healing, urination, swelling, edema, union of wound edges and status of sutures. The results showed that in group A, the wound was healed in $7.00 \pm 0.89$ days and in group B it was healed in $9.00 \pm 1.41$ days. It was observed that silk suture material performed better than nylon in group A than group B for wound healing. After wound healing, normal urination and normal food intake was observed in group A as compare to group B. It was concluded that silk suture provided better and fast wound healing process as compared to nylon suture material in all cats. It is suggested that silk suture is reliable for perineal urethrostomy procedure, because of easily available and have no any complications.

Keywords: Cat; Nylon suture; Silk suture; Urethrostomy; Wound healing

\section{Introduction}

The suture materials have important role in the wound healing to enable reconstruction and reassemble tissues separation by the surgery [1]. Surgical interventions require wound closure using a suitable suture material. Different types of suture materials are used. For example, silk suture material and nylon suture material. Silk suture is a braided, naturally occurring non-absorbable suture material and fibers are made by silkworm larva. This suture material is used for number of reasons for example; better wound handling, less complications, easy 
access and cheap $[2,3]$. During the past 25 years, a range of degradable synthetic sutures has dominated the suture market. However, silk is still popular in ocular, neural, and cardiovascular surgery owing to its advantageous characteristics [4].

Nylon is a polyamide synthetic nonabsorbable suture material. But its drawback is that it is difficult to handle and has poor knot security $[5,6]$ can be extruded into a non-capillary and is made up of monofilament thread or interlaced. It has many advantages such as it creates less tissue reaction, good tensile strength and used for skin wound closure [7]. After embedding nylon monofilament suture material drops about $30 \%$ of its unique tensile strength by two years because of its chemical breakdown, while multifilament nylon suture damages basically $100 \%$ of its tensile strength after six months in soft tissues. Retention of urine is one of the common and major clinical problems of a male cat [8] and many other animals are dying without treatment. Urolithiasis is a second biggest cause of death in cats [9] and this problem can be fixed by performing perineal urethrostomy. However, perineal urethtrostomy is a surgical procedure used for creation of a permanent opening through perineal region into a male cat urethra. This procedure is used for removal of urinary calculi that cannot be removed by flushing [10]. Mostly cause of retention of urine occurs due to calculus and obstruction of the urine flow. In such condition, sturvite crystals, calcium oxalate crystals cell accumulation representing to urinary tract infection and hardness of these structures. It has been noticed that urolithiasis is a most common problem [11]. Where, Wilson and Harrison procedure is the best method to perform perineal urethrostomy in a male cat. Main reason of calculi formation is the stone and calculi trapped at narrow space of urethra at sigmoid flexure or trapped at preputial opening. The calculi are mostly found in urinary bladder, but can also be occurred in renal pelvis and urethra [12]. Urinary obstruction may also occur due to cystitis. Moreover, calculi formation occurs usually from the combination of nutritional, physiological, seasonal, age, sex and management factors. Best treatment of urolithiasis is a surgical, once the obstruction is completed, then removal of calculi may be carried out directly or indirectly by passing the obstruction [13]. Perineal urthrostomy is a key solution to solve the problem in affected male cats. Sutures are used to make countless surgical techniques and used on both in animals as well as humans [14]. The choice of suture material also affects the wound healing; therefore, the lowest suture material size should be used for minimizing the body reaction. Among suture materials, chromic catgut and silk suture are most commonly used for surgical wound closure in veterinary surgery [15].

A wound is an unpreventable event of life which ascends due to physical, chemical injury and microbial contamination that cause damage and penetrate into the skin layers [16]. Sutures play major role in wound repairing and provide better hemostasis and also support for faster healing [6, 17]. Wound healing requires interaction between a variety of cells including fibroblast and myo fibroblast [18]. Therefore, wound healing and its assessment is important for skin wound healing. In all above surgical conditions, skin is incised and then closed with different nonabsorbable suture material.

Only few studies [10-12] have reported for perineal urthrostomy wound healing using two different suture materials for closure of urthrostomy wound in cats. The present study was based on assessment of skin wound healing process by physical examination and whether which suture is 
better for perineal urethrostomy wound healing in cat. Keeping in view the significance, the study is to assess the wound healing after urethrostomy and closing the wound using silk or nylon suture in a cat. This study will provide better treatment for clinical cases of cats.

It was hypothesized that silk suture would provide better urethrostomy wound healing in cat as compared to nylon suture, Silk suture provides good skin wound healing [19]. The study was conducted with aims (i) to compare skin wound healing after urethrostomy process using silk and nylon in cat, (ii) to determine the complications of wound healing in cats between silk and nylon after urethrostomy.

\section{Materials and Methods}

\section{Animal experiment and location of study}

The present study was carried out on 12 healthy male cats at the Department of
Surgery and Obstetrics, Faculty of Animal Husbandry and Veterinary Science, Sindh Agriculture University, Tandojam. Cats were trapped from Tandojam and its vicinity with the possible age of 3-5 months old randomly. They were kept at the Indoor Patient Ward of the Department of Surgery and Obstetrics, Sindh Agriculture University Tandojam so that they can adapt their surroundings for minimum period of one week. The required food (meat and milk) and water was offered two times in a day.

\section{Experimental design}

The experiment was comprised of 12 male cats. These cats were separated into two groups (Group-A and Group-B) placing six animals in each group. The following two suture materials were applied on the skin of cats (Table 1).

Table 1. Experimental Design

\begin{tabular}{|c|c|c|c|c|}
\hline Group & No. of animals & Procedure & Suture material & Suture techniques \\
\hline A & 06 & Urethrostomy & $\begin{array}{c}\text { Silk 3/0 } \\
\text { (Ghazali Brothers) }\end{array}$ & Simple interrupted \\
\hline B & 06 & Urethrostomy & $\begin{array}{c}\text { Nylon 3/0 (Foosin medical supplies } \\
\text { inc Ltd.) }\end{array}$ & Simple interrupted \\
\hline Total & 12 & & & \\
\hline
\end{tabular}

$\mathrm{A}=$ Silk (Non-absorbable suture material) marketed by Ghazali Brothers Karachi,

$\mathrm{B}=$ Nylon (Non-absorbable suture material) Foosin medical supplies inc Ltd

\section{Pre- operative preparation}

Preoperative consideration was performed to increase the outcome of surgery, reduce the risk for problems and make the surgery as harmless and effective as possible. Healthy animals (male cats) were physically examined and were used for this experiment. All cats were off feed for 12 hours before surgery and after premedication the operative site of animal was prepared, hairs were removed from perineal region with using hair clipper blade No.40. Normal physiological parameters such as rectal temperature, heart rate and respiratory rate were recorded before surgery, during surgery and after surgery. The cats were given anesthesia lasts for at least half an hour before the start of each experiment.

\section{Anesthesia}

Cats were premedictated with Acepromazine $0.03 \mathrm{mg} / \mathrm{kg}$, Xylazine $0.5 \mathrm{mg} / \mathrm{kg}$ body weight intramuscularly for sedation. General anesthetic agent Ketamine hydrochloride $6 \mathrm{mg} / \mathrm{kg}$ body weight was also administered using $1 \mathrm{ml}$ disposable syringe.

\section{Surgical procedure}

The experiment was conducted under aseptic conditions in the Dr, Arz 
Muhammad Unar Surgery hall in the Department of surgery and obstetrics, Sindh Agriculture University, Tandojam. The male cats were placed on dorsal recumbancy after anesthesia tail was folded cranially and hairs were clipped with clipper blade No.40. After that, operative site of a animal was sterilized with povidone for performing urethrostomy procedure. Before incision tom catheter sized (14 $\mathrm{mm}$ diameter) was inserted into the urethra of a cat till the completion of surgery and under the guidance of this tom catheter an inverted crescent shape incision was made using scalpel handle No.03 and through this incision intact male cats were castrated. An elliptical incision of three inch was given around the scrotum and prepuce initially. Penis was located in granular tissue of perineal region which was dissected sharply and bluntly from the surrounding connective tissues. Penis dissection was continued until it was free from all its attachments. The retractor penile muscle on the dorsal part of the penis was cut until the balbourethral glands and penile urethra were observed. The urethral mucosa was anastomosed to perineal skin region using silk $2 / 0$ and Nylon $2 / 0$ suture in an interrupted pattern and in last skin wound was closed.

\section{Post-operative care}

Each animal was administered with Pencillin G $0.5 \mathrm{cc}$ after surgery and meloxicame at $0.3 \mathrm{cc}$ intramuscular for one week. Containing wound, dressing was done with applying Povidone on the wound externally. However, the soft food milk and cake was offered to the operating animals 1day post-surgery. The operative site of all cats was monitored twice time in a day to assess wound healing, hemorrhage, stitches removing, edema, maggot infestation and swelling (Table 2).

Table 2. Showing parameters recording post-surgery in cats

\begin{tabular}{|c|c|}
\hline Criteria & Healing Status \\
\hline Suture dehiscence & Present/Absent \\
\hline Maggot infestation & Present/Absent \\
\hline Wound infection & Present/Absent \\
\hline Swelling & Present/Absent \\
\hline Dysuria & Present/Absent \\
\hline Hemorrhage & Present/Absent \\
\hline
\end{tabular}

\section{Observation and recordings}

Animals were examined during the whole period of study for visual observations such as salivation, swelling at the site of incision, urination, edema, union of wound edges and status of sutures were observed from the operation site in each cat. All animals were observed twice daily (morning and evening).

\section{Skin wound healing parameters}

\section{Statically analysis}

The data were subjected to ANOVA to compare the mean value using SPSS 16.0. Differences between means were assessed for significance at $\mathrm{p}<0.05$ using least significant difference (LSD) [20].

\section{Results}

This experimental study was performed on healthy adult male intact cats. Perineal urethrostomy was perfomed under general anesthesia and wound was closed using two different suture materials i.e. silk and nylon to compare the urethrostomy wound healing. Total 12 cats were used and they were divided into two groups (Group A and B) placing 6 cats per group.

In group A, 6 cats were used and perineal urethrostomy was performed then wound 
was closed with silk suture natural (nonabsorbable) and in group B, 6 cats were used and perineal urethrostomy was performed and wound was sutured with nylon suture synthetic (non absorbable). In all cats perineal urethrostomy was performed using scalpel under general anesthesia. The wound was closed with silk $2 / 0$ in group $\mathrm{A}$ and nylon $2 / 0$ suture in group B. The cats were observed for two weeks post surgery to evaluate the wound healing process. The results obtained from this study are described as under;

Incision length $(\mathbf{c m})$

Incision length in both groups A and B was $3.00 \pm 00 \mathrm{~cm}$. While, the wound healing of cats in group A was 7.00 \pm 0.89 days and in group B was $9.00 \pm 1.41$ days. The results showed that wound healing was better and very fast in group A compared to group B. Silk suture material was superior in terms of early wound healing compared to nylon (Table 3).

Table 3. Incision length (cm) and wound healing (days)

\begin{tabular}{|c|c|c|c|}
\hline \multirow{2}{*}{ Animals } & \multirow{2}{*}{ Incision length } & \multicolumn{2}{|c|}{ Wound healing (days) } \\
\cline { 3 - 4 } & & Group A & Group B \\
\hline 1 & $3.00 \pm 00$ & 8 & 8 \\
\hline 2 & $3.00 \pm 00$ & 6 & 9 \\
\hline 3 & $3.00 \pm 00$ & 7 & 10 \\
\hline 4 & $3.00 \pm 00$ & 6 & 7 \\
\hline 5 & $3.00 \pm 00$ & 8 & 11 \\
\hline 6 & $3.00 \pm 00$ & 7 & 9 \\
\hline Mean & $3.00 \pm 00$ & $7.00 \pm 0.89$ & $9.00 \pm 1.41$ \\
\hline
\end{tabular}

\section{Number of stitches}

The incised wound of cats in group A was closed using $(6 \pm 0)$ number of stitches, whereas group B were closed using

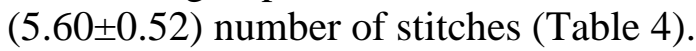

\section{Postoperative complications}

The following complications after surgery were observed in all animals on daily basis which are presented in (Table 5). In Group A, complications such as suture dehiscence, maggot infestation, wound infection, swelling, dysuria and hemorrhage was absent and in group B swelling present in one animal and dysuria was seen in two animals.

Table 4. Number of stitches for closure of perineal urethrostomy wound

\begin{tabular}{|c|c|c|}
\hline Parameter & Group A & Group B \\
\hline Number of stitches & $6 \pm 0.00$ & $5.60 \pm 0.52$ \\
\hline
\end{tabular}

Table 5. Postoperative complications of wound healing in cats

\begin{tabular}{|c|c|c|}
\hline Parameters & Group A (Silk) & Group B (Nylon) \\
\hline Suture dehiscence & Absent in all animals & Absent in all animals \\
\hline Maggot infestation & Absent in all animals & Absent in all animals \\
\hline Wound infection & Absent in all animals & Absent in all animals \\
\hline Swelling & Absent in all animals & Present in one animals \\
\hline Dysuria & Absent in all animals & Present in two animals \\
\hline Hemorrhage & Absent in all animals & Absent in all animals \\
\hline
\end{tabular}




\section{Discussion}

Total 12 male adult cats were used in present research divided into two groups (Group A and Group B). Furthermore three different anesthetic drugs were used to perform perineal urethrostomy (P.U) procedure. All animals were kept in same hygienic condition and look after twice a day. Two different suture materials such as silk $2 / 0$ and nylon $2 / 0$ were used to assess better suture material for faster wound healing after perineal urethrostomy. In present study there were no any animal died and all experimental animals survived after surgery. In this study all cats were anesthetized with Ketamine $5 \mathrm{mg} / \mathrm{kg}$, Xylazine $0.25 \mathrm{mg} / \mathrm{kg}$ and Acepromazine $0.25 \mathrm{mg} / \mathrm{kg}$ intramuscularly.

In study, Cashmore and Ladlow [21] evaluated the perineal urethrostomy technique in male dogs for perineal hypospadias. However, in present study perineal urethrostomy was successfully performed in male cats. Aim of this study was to correct anatomical abnormality to minimize the risk of recurrent urinary tract infection in male cats [22]. While, urethrostomy procedure is performed used to minimize the complication related with mucosal tissues however, it was recommended the approval of these scientists [23].

The preceding findings revealed that the selection of urethrostomy and their various types that mainly depends upon length of healthy urethra, the condition of perineal preputial and scrotal skin and surgeon preference. Moreover, current study specifically focused upon perineal urethrostmy procedure which was performed on male adult cats [24].

\section{Conclusion}

Findings of this study showed that in Group A wound was healed in $7.00 \pm 0.89$ days and in group B wound was healed in $9.00 \pm 1.41$ days. Some complications like hemorrhage, maggot infestation, wound infection, swelling and dysuria was absent in group $\mathrm{A}$ as compared to group B. While, there were some post surgery complications were found in group B such as swelling, dysuria and delay wound healing. Silk used for closure of perineal urethrostomy wound resulted excellent wound healing. Postoperative complication of perineal urethrostomy was not found in any cats of (group A). While, in (group B) swelling and dysuria were observed. On the basis of the present study, following recommendations/suggestions are made: Silk suture material may be used for repair of urinary tract for obstruction when perineal urethrostomy is performed as compared to nylon suture material. Further study is required to investigate the other suture materials for early wound healing without postoperative complications in cats.

\section{Authors' contributions}

Conceived and designed the experiments: AN Tunio \& TH Khaskhali, Performed the experiments: TH Khaskhali, JK Soothar \& SK Oad, Analyzed the data: TH Khaskhali \& JA Dhiloo, Wrote the paper: $\mathrm{TH}$ Khaskhali \& KI Tunio.

\section{Reference}

1. Banche G, Roana J, Mandras N, Amasio M, Gallesio C \& Allizond V (2007). Microbial adherence on various intraoral suture materials in patients undergoing dental surgery. J Oral Maxillofac Surg 65(8): 1503-7.

2. Dunn D (2007). Wound Closure Manual. Ethicon: A Johnson and Johnson Company, USA. 9-40.

3. Fossum $\mathrm{T}$ (2002). Biomaterial suturing and hemostasis. In: Fossum TW, Hedlund, C.S and Johnson, AL, editors. Small animal surgery: $2^{\text {nd }}$ edition. Mosby Publishing, St, Louis, MO. pp. 43-59.

4. Thilagavathi G \& Viju S (2015). Silk as a suture material. Advances in Silk Science and Technology Woodhead Publishing Series in Textiles. pp 219-232. 
5. Neath PJ (2005). Equipment and surgical instrumentation/surgical biometrical, In:William JM,Niles JD (Eds). BSAVA. Manual of canine and feline abdominal surgery $\left(1^{\text {st }}\right.$ eds $)$ BSAVA, Gloucestor, UK, pp 23-27.

6. Schmiedt CW (2012). Suture material, tissues staplers, ligation devices and closure methods. In: Tobias KM, Johnson SA (Eds). Veterinary small animal surgery, Saunders, St, Louis USA, pp. 187-200.

7. Charles DK, David JW \& Jerry HJ (2009). Importance of suture material. Hand Book of Veterinary Merck, $1^{\text {st }}$ Edition, pp. 88-93.

8. Amarpal KP, Aithal HP, Pawde AM, Singh T \& Pratap K (2004). Incidence of urolithiasis: A retrospective study of five years. Indian J Animal Sci 74: 175-77.

9. Bani IZA, Al-Zghoul MF, Al-Majali AM \& Khraim NM (2007). Effects of castration on penile and urethral development. Bulgarian J Vet Med 10(1): 29-34.

10. Vnuk D, Maticic D, Kreszinger M, Radisic B, Kos J, Lipar M \& Babic T (2014). A modified salvage technique in surgical repair of perineal hernia in dogs using polypropylene mesh. Vet Med 51(3): 111-117.

11. Igna JA (2008). A comparison of two different suture patterns for closure of canine ovariohysterectomy. Canadian Vet J 43: 699-702.

12. Mehrjerdi G, Kumar A \& Braun U (2012). Ultrasonographic examination of the left kidney, the urinary bladder and the urethra. Zentral blatt Vet Med 40(1): 1-9.

13. Ewoldt JM, Jones ML \& Miesner MD (2008). Surgery of obstructive urolithiasis in ruminants. Vet Clin North Am Food Anim Pract 24: 455-65.

14. Walter OBF, Wouters F, Wouters AAB, Bernis VMO, Lopes LR \& Andreollo NA
(2013). Comparative study of cotton, polyglactin and polyglecaprone sutures in intestinal anastomoses in rabbits. $J$ Animal Sci 55(2): 159-156.

15. Fossum TW (1997). Small Animal Surgery. Mosby. St. Louis, p. 43.

16. Werner S \& Grose R (2003). Regulation of wound healing by growth factors and cytokines. Physiology Review, 83: 835870.

17. Tam RH, Bell RJ, Dowling BA \& Dart AJ (2003). Suture materials, composition and application in veterinary wound repair. Australian Vet J 81(3): 140-145.

18. Robert F (2004). Diegelmann, Meslissa CE. Wound healing: An over view of acute, fibrotic and delayed healing. Front Biosci 283-9.

19. Soderberg TA (1995). Trace elements in normal and impaired wound healing. In: Altmeyer P, Hoffmann K, El Gammal S, Hutchinson J. Eds. Wound Healing and Skin Physiology. Springer-Verlag 6: 18399.

20. Steel RG, Torrie JH \& Dickey DA (1997). Principles and Procedures of Statistics. A Biometrical Approach 3rd Edition. McGraw Hill book Co. Inc. New York, USA.

21. Cashmore A \& Ladlow EA (2012). Tissue reactivity to poliglecaprone 25 in the feline linea alba. Vet Surg 28: 466471.

22. Adelsberger RJ \& Smeak PW (2007). The rabbit. Aeromed. REUS. 21, No. 6. USAF School of Aerospace Medicine, Brooks Airforce Base, San Antonio TX 1973.

23. Bleedom MR \& Bjorling A (2012). Lymphocytes function in wound healing and following injury. British J Surg 85: 444-460.

24. Pavletic GS \& Wysocki A (2007). Interactions between extracellular matrix and growth factors in wound healing. Wound Repair Regen 17: 153-62. 